Check for updates

Cite this: RSC Adv., 2018, 8, 16626

\title{
Galvanic corrosion of duplex corrosion-resistant steel rebars under carbonated concrete conditions
}

\author{
Jinyang Jiang, (D) *a Hong-yan Chu, (D) *b Yao Liu, ${ }^{a}$ Danqian Wang, ${ }^{a}$ Dong Guo ${ }^{c}$
} and Wei Sun ${ }^{a}$

Galvanic corrosion between two different kinds of steel rebars is usually the case in practical engineering. Open circuit potential (OCP), linear polarization resistance (LPR), Tafel polarization, scanning vibrating electrode technique (SVET), scanning electron microscopy (SEM) and reflection digital holographic microscopy (DHM) were used to study the galvanic corrosion of a novel corrosion-resistant steel bar (CR) and low-carbon steel bar (LC) in simulated concrete pore solutions with different $\mathrm{pH}$ values and a chloride ion concentration of $5 \mathrm{~mol} \mathrm{~L}^{-1}$. The $\mathrm{pH}$ of the simulated concrete pore solution had a significant impact on the corrosion behaviour of CR and LC when they were in contact and were attacked by chloride ions. As the $\mathrm{pH}$ increased, the potential between CR and LC decreased and the driving force for the galvanic corrosion decreased. When the $\mathrm{pH}$ was 9.0, galvanic corrosion occurred on CR and LC at a high rate. CR developed local pitting corrosion, while LC mainly developed uniform corrosion, each with an apparent accumulation of corrosion products on the sample's surfaces. When the $\mathrm{pH}$ was 11.3, galvanic corrosion occurred when CR and LC were in contact. CR showed a relatively smooth surface, with only a small amount of pitting corrosion. In contrast, LC developed both pitting corrosion and uniform corrosion, and both apparent pitting corrosion and an accumulation of corrosion

Received 18th April 2018 Accepted 30th April 2018 DOI: 10.1039/c8ra03320j rsc.li/rsc-advances products on the sample surface were observed. When the $\mathrm{pH}$ was 13.6, there was no galvanic corrosion when CR and LC were in contact; the corrosion of CR and LC was mainly pitting corrosion. Therefore, for regions with chloride ion corrosion and severe carbonization, the galvanic corrosion between $C R$ and LC cannot be ignored.

\section{Introduction}

Currently, reinforced concrete is one of the most widely used construction materials, due to its high mechanical resistance and economical manufacturing. ${ }^{1,2}$ Research has shown that chloride ions and the carbonization of concrete are the main causes of the corrosion of rebars, ${ }^{3}$ which mainly contributes to the degeneration of the concrete's structure. ${ }^{4-6}$ Developing novel corrosion resistant rebars is an effective approach to fundamentally avoid this corrosion and improve the durability of reinforced concrete. In practical engineering, mixed use of novel corrosion resistant rebars and low carbon steel rebars is usually the case. For example, steel alloys with excellent corrosion resistance are normally used for the longitudinal bar of the concrete, whereas low carbon steel is normally used for stirrups. Thus, contact between corrosion resistant rebars and regular rebars exists and an electron channel forms due to the potential

\footnotetext{
${ }^{a}$ School of Materials Science and Engineering, Southeast University, Nanjing 211189, China. E-mail: jiangjinyang16@163.com

${ }^{b}$ College of Civil Engineering, Nanjing Forestry University, Nanjing 210037, China. E-mail: chuhongyan@njfu.edu.cn

${ }^{c}$ Naval Institute of Engineering Design and Research, PLA, Beijing 100070, China
}

difference between these two kinds of steel. As a result, galvanic corrosion between these two kinds of steel occurs with concrete acting as the electrolyte. These differences are particularly pronounced when carbonization and chloride ion corrosion occur in concrete.

The passivation and corrosion of low carbon steel has been investigated for decades, ${ }^{7,8}$ while the passivation and corrosion mechanism of novel corrosion resistant steel rebars is still in discussion. Ai et al. ${ }^{9}$ investigated the corrosion performance of alloyed corrosion-resistant rebars in simulated concrete pore solutions with different $\mathrm{pH}$ values. For the corrosion-resistant rebar, the lower the alkalinity of the solution is, the easier the steel is passivated and the better the corrosion-resistant properties of the rebar will be. In contrast, for regular low-carbon steel, the lower the alkalinity of the solution is, the more difficult the passivation is and the poorer the corrosion-resistant properties of the rebar will be. Jiang et al..$^{10}$ studied the formation mechanism of the passive film on a new corrosion-resistant steel in a simulated concrete pore solution. Shi et al. ${ }^{11}$ investigated the influence of chloride concentration and prepassivation on the pitting corrosion resistance of low-alloy reinforcing steel in a simulated concrete pore solution. When the chloride ion concentration reached $1.0 \mathrm{~mol} \mathrm{~L}^{-1}$ in the 
simulated concrete pore solution, the low-alloy reinforcing steel exhibited better corrosion performance than low-carbon steel. Only two-dimensional microstructure of rebar subjected to different simulated concrete pore solution was investigated in these studies.

Up to now, although there are many reports on the corrosion behaviour of alloy steels in simulated concrete pore solutions, there are only a few reports about the galvanic corrosion that probably occurs when low-carbon steel and alloy steel are used together. Dong et al. ${ }^{12}$ investigated the galvanic corrosion of stainless steel and showed that the galvanic corrosion and selfcorrosion of carbon steel were reinforced in the sandcontaining solution. Krogstad et al. ${ }^{13}$ examined the corrosion behaviour of galvanically coupled Nickel-Aluminium Bronze (NAB) and stainless steel during three weeks of exposure to natural seawater and showed that the galvanic current was limited by the cathodic efficiency of stainless steel, while the coupled potential was dictated by the NAB. Abreu et al. ${ }^{\mathbf{1 4}}$ studied the galvanic coupling between carbon steel and austenitic stainless steel in sodium hydroxide solution. No significant risk of galvanic corrosion of carbon steel and stainless steel exists under the passivation of steel or chloride ion corrosion. Ai et al. ${ }^{15}$ studied the adsorption behaviour of anionic inhibitor on galvanic electrode in $\mathrm{NaCl}$ solution, and they pointed out that the galvanic corrosion of N80/S31803 can be inhibited by anionic inhibitor. The galvanic current densities between the individual aluminium alloys and the carbon fibre composites were measured by Liu et al., ${ }^{\mathbf{1 6}}$ and the experimental results indicated that a higher coupling current density was significant for the AA1050 alloy compared to the AA7075-T6 alloy. Zhang et al. ${ }^{17}$ carried out an investigation on $\mathrm{CO}_{2}$ corrosion behavior of carbon steel with imidazoline-based inhibitor subjected to $\mathrm{NaCl}$ solution, and they found that the $\mathrm{H}$ steel (coarse laminar pearlite) suffered more severe localized corrosion than $\mathrm{T}$ steel (globular and shot rod shaped pearlite), because the larger driving force for galvanic corrosion. At present, the galvanic corrosion of different metals under the interaction of a single factor has been investigated. However, there are almost no studies about the probable galvanic corrosion of alloy steel and regular, low-carbon steel in the presence of both carbonization and chloride corrosion. As a novel corrosion-resistant rebar, information on microstructure, open circuit potential (OCP), linear polarization resistance (LRP), and Tafel curves of galvanic corrosion between corrosion-resistant rebar and ordinary rebar is rather limited, and needs to be updated.

In the present report, the macroscale corrosion of new corrosion-resistant rebar (CR) and ordinary rebar (LC) in simulated concrete pore solutions with different $\mathrm{pH}$ 's under the attack of chloride ions was tested. The microscale distribution of the current density in the electrochemical reaction between CR and LC was also investigated in the work. Both the surface morphology and the surface elemental compositions of the rebars were analysed, and the three-dimensional morphology of the rebar surface from the micro- and nano-scales was studied in the paper. The galvanic corrosion of the novel, corrosionresistant rebar and ordinary rebar in simulated concrete pore solutions with different pH's under the attack of chloride ions was thus investigated.

\section{Experimental section}

\section{Raw materials}

Comparative investigations were conducted between new Cr10Mo1 corrosion-resistant alloy steel (CR) bar and low-carbon steel (LC) bar. The chemical composition of two kind of steels is shown in Table 1.

The simulated concrete pore solution is primary affected by its chemical composition and $\mathrm{pH},{ }^{18}$ but there are no uniform standards for the preparation of the simulated concrete pore solution. The simulated concrete pore solution used in the work is shown in Table 2. In order to consider the effect of carbonation, the simulated concrete pore solution with different $\mathrm{pH}$ was prepared, namely, 9.0, 11.3, and 13.6. For convenience, the three different simulated concrete pore solutions were marked as LA, MA, and HA in Table 2, which denoted weakly alkaline $(\mathrm{pH}=9.0)$, moderately alkaline $(\mathrm{pH}=11.3)$, and highly alkaline $(\mathrm{pH}=13.6)$ of solution, respectively. Chloride penetration into concrete is the main cause of steel corrosion, ${ }^{19}$ and passive film on the surface of steel bar is destroyed due to chloride ion when the chloride concentration is higher than that of critical chloride concentration of steel bar. ${ }^{20-22}$ According to our previous study, the critical chloride concentration of CR steel bar is 5 mol L ${ }^{-1}$. Thus, a high concentration $\left(5 \mathrm{~mol} \mathrm{~L}^{-1}\right)$ of chloride ion in the simulated pore solution was used in the study so as to accelerate the corrosion of the CR steel. According to Table 2, the simulated concrete pore solutions were prepared with vacuum filtration by utilizing a $2.5 \mu \mathrm{m}$ filter to ensure that the solutions are free from suspensions.

\section{Experimental methods}

Electrochemical measurement. The size of the steel bars used in the work was $\Phi 20 \mathrm{~mm} \times 10 \mathrm{~mm}$ (diameter is $20 \mathrm{~mm}$, and length is $10 \mathrm{~mm}$ ). The bottoms of the bars were utilized as the testing surfaces. Each testing surface was polished stepwise with increasing grades (\#200, \#600, \#1000, and \#2000) of SiC sandpaper, and the polishing time was about $5 \mathrm{~min}$ for each kind of sandpaper. After washing with deionised water, the surface was polished to a mirror finish with $0.25 \mu \mathrm{m}$ diamond polishing liquid. The bars were then cleaned, and the surface impurities were removed with alcohol. The specimens were dried with a hair dryer and immediately placed into the etching tank.

The specimens were immersed in the simulated concrete pore solutions with different $\mathrm{pH}$ for $72 \mathrm{~h}$, and then the corrosion behaviour of bars were measured by OCP, LPR, and Tafel

Table 1 Chemical composition of the experimental steel bars (wt\%)

\begin{tabular}{lllllll}
\hline & $\mathrm{C}$ & $\mathrm{Si}$ & $\mathrm{Mn}$ & $\mathrm{Cr}$ & $\mathrm{Mo}$ & $\mathrm{Fe}$ \\
\hline $\mathrm{LC}$ & 0.22 & 0.53 & 1.44 & - & - & 97.81 \\
$\mathrm{CR}$ & 0.01 & 0.49 & 1.49 & 10.36 & 1.16 & 86.49
\end{tabular}


Table 2 Composition of the simulated concrete pore solution (wt\%)

\begin{tabular}{llllllr}
\hline Composition & $\mathrm{KOH} \mathrm{mol} \mathrm{L}$ & $\mathrm{NaOH} \mathrm{mol} \mathrm{L}$ & $\mathrm{Ca}(\mathrm{OH})_{2} \mathrm{~mol} \mathrm{~L}^{-1}$ & $\mathrm{Na}_{2} \mathrm{CO}_{3} \mathrm{~mol} \mathrm{~L}^{-1}$ & $\mathrm{NaHCO}_{3} \mathrm{~mol} \mathrm{~L}^{-1}$ & $\mathrm{pH}^{2} \mathrm{NaCl} \mathrm{mol} \mathrm{L}^{-1}$ \\
\hline LA & 0 & 0 & 0 & 0.025 & 0.025 & 5.0 \\
MA & 0.6 & 0.2 & 0.03 & 0 & 0.83 & 5 \\
HA & 0.6 & 0.2 & 0.03 & 0 & 0 & 11.3 \\
\end{tabular}

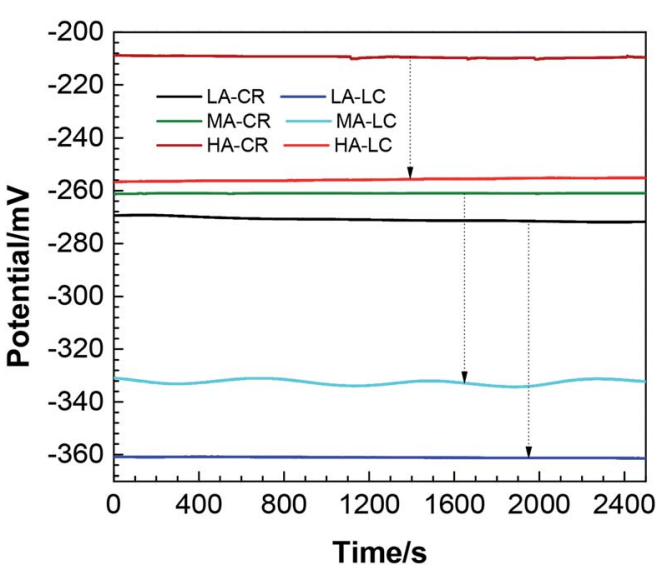

Fig. 1 Open circuit potentials of the two steel bars in different solutions (the labels LA, MA, and HA denote which solution the CR or LC is immersed in).

polarization. The electrochemical test was performed with the PARSTAT 4000 electrochemical workstation. A three-electrode measurement system was used; i.e., the reinforced bars were set as the working electrode, the saturated calomel electrode was set as the reference electrode, and the platinum electrode was the auxiliary electrode. The test was performed at room temperature $\left(25 \pm 1{ }^{\circ} \mathrm{C}\right)$. All electrochemical tests were performed after the open potentials working electrode was stabilised. The range of the linear polarisation resistance is $\pm 10 \mathrm{mV}$

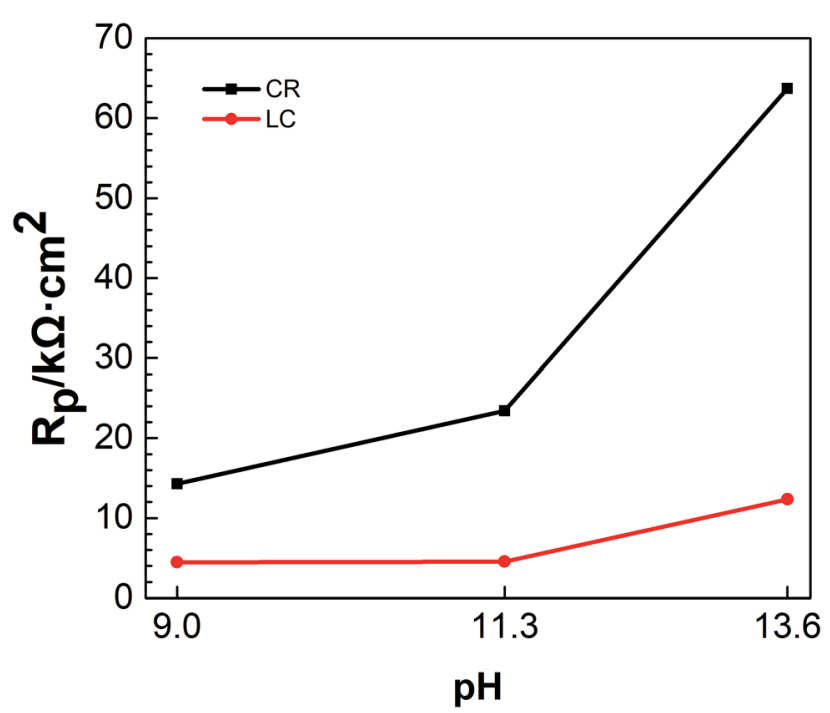

Fig. 2 Linear polarization resistances of the two steel bars in simulated concrete pore solutions with different $\mathrm{pH}$. vs. $E_{\text {corr }}$ at a scanning speed of $10 \mathrm{mV} \mathrm{m^{-1 }}$. The potentiodynamic current-potential curves were recorded by polarizing the specimen to $-250 \mathrm{mV}$ cathodically and $+250 \mathrm{mV}$ anodically with respect to OCP at a scan rate of $0.5 \mathrm{mV} \mathrm{s}^{-1}$. It should be pointed out that the galvanic coupling related to the SEVT testing was simulated by mounting in epoxy resin one new corrosionresistant steel rod nest to one low-carbon steel rod, with about a $2 \mathrm{~mm}$ gap between them. At the rear of the mounting, an electrical connection was made with Sn welding.

Micro-measurement. The size of specimens used for micromeasurement was $1 \mathrm{~mm} \times 1 \mathrm{~mm} \times 10 \mathrm{~mm}$, and the specimens were embedded into epoxy sleeve. The upper surfaces of the specimens were used for micro-measurement, and the lower surfaces of them were connected with conductive adhesive. The testing surface preparation of the specimens used for micromeasurement was the same with those of specimens used for electrochemical measurement, as mentioned above. The specimens were also immersed in the simulated concrete pore solutions with different $\mathrm{pH}$ for $72 \mathrm{~h}$, and then the corrosion behaviour of bars were measured via scanning vibrating electrode technique (SVET), scanning electron microscopy (SEM), and reflection digital holographic microscopy (DHM). In order to detect the current density of $(\mathrm{CR}+\mathrm{LC})$ specimens, an $\mathrm{AE}$ PSDA-2 scanning vibrating electrode technique system was used in the study, and probe is made of PI0036.0A10 platinumiridium alloy. The amplitude and frequency of vibration is 20 $\mu \mathrm{m}$ and $83 \mathrm{~Hz}$, respectively. The scanning electron microscope used in this experiment was a FEI SIRION-100 field emission scanning electron microscope. The energy dispersive spectrometer (EDS) analysis was also performed to carry out elemental analyses. A Lyncee Tec SA digital holographic microscope, a type of reflective digital holographic microscope, with a view field of $5 \mathrm{~mm}$, was used in the paper. The resolution along the $x$ - and $y$-axes is $>300 \mathrm{~nm}$, and the resolution along the $z$-axis is $>0.6 \mathrm{~nm}$. The surfaces of the samples etched for different durations was viewed with a lens of $20 \times$ magnification.

\section{Results and discussion}

\section{Electrochemical test}

Open circuit potential. Fig. 1 shows the open circuit potentials of the two steel bars in different solutions.

It can be seen from Fig. 1 that the open circuit potentials of CR and LC attacked by chloride ions in simulated concrete pore solutions with different $\mathrm{pH}$ all exhibited stable states. When the $\mathrm{pH}$ was 9.0, the stable open circuit potentials of CR and LC were approximately $-270 \mathrm{mV}$ and $-360 \mathrm{mV}$, respectively. When the $\mathrm{pH}$ was 11, the stable open circuit potentials of CR and LC were 

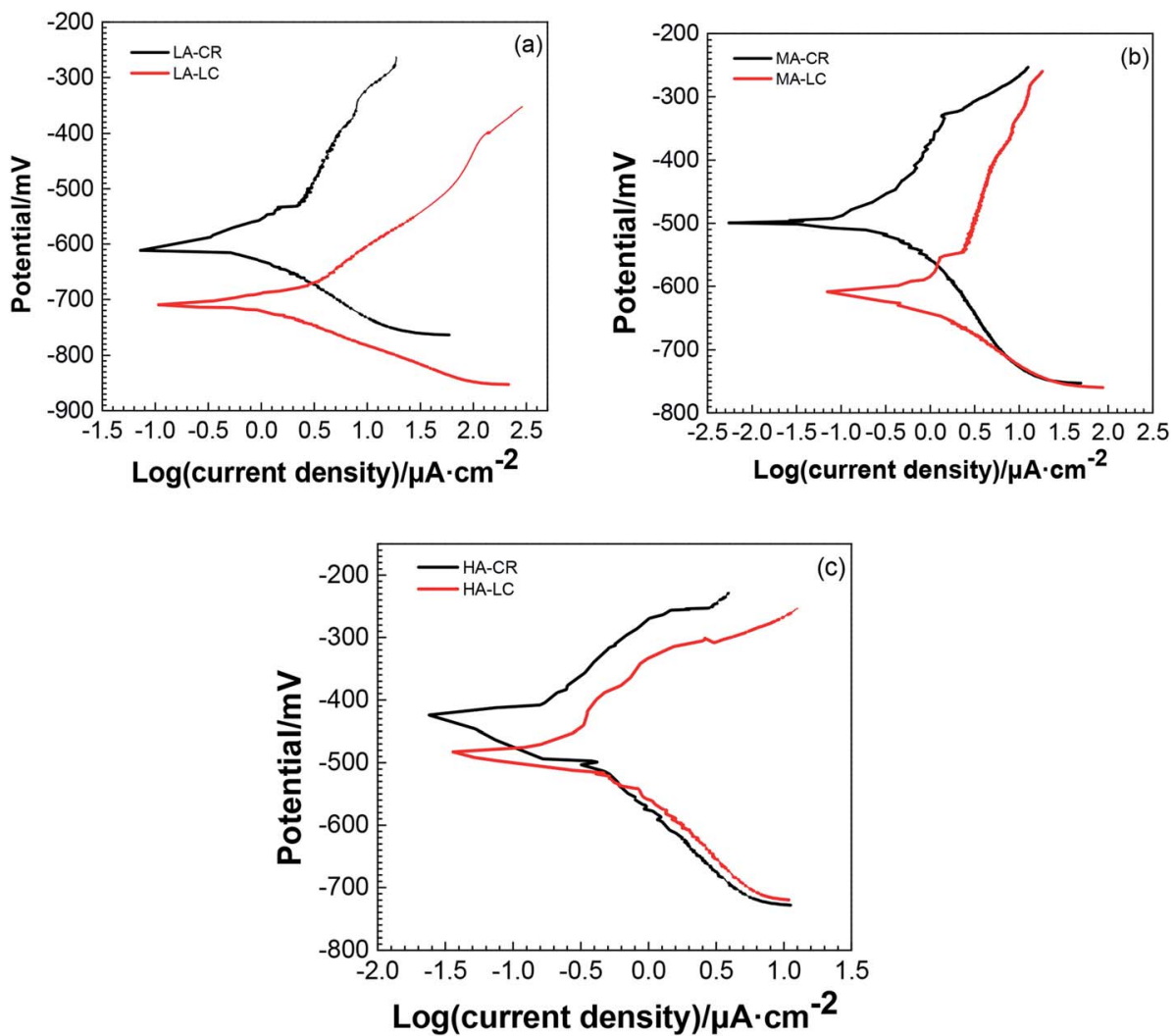

Fig. 3 Tafel curves of the two steel bars in simulated concrete pore solutions with different $\mathrm{pH}$ : (a) $\mathrm{pH}=9.0$; (b) $\mathrm{pH}=11.3$; (c) $\mathrm{pH}=13.6$.

approximately $-260 \mathrm{mV}$ and $-330 \mathrm{mV}$, respectively. When the $\mathrm{pH}$ was 13.6, the stable open circuit potentials of CR and LC were approximately $-210 \mathrm{mV}$ and $-256 \mathrm{mV}$, respectively. At the same $\mathrm{pH}$, the OCP of CR was always lower than that of LC, and the corrosion thermodynamic tendency of LC was always greater than that of $\mathrm{CR}^{.23}$ As a result, in the galvanic coupling of CR and LC, LC serves as the anode and CR as the cathode. Additionally, with increasing $\mathrm{pH}$, electrode reversal does not occur. Additionally, Fig. 1 shows that with increasing $\mathrm{pH}$, the difference between the OCPs of the steel bars decreased, indicating that the driving force for the galvanic corrosion also decreased. ${ }^{24}$ In particular, when the $\mathrm{pH}$ was 13.6 , the difference between the OCPs of CR and LC was only $50 \mathrm{mV}$. In theory, this constitutes a driving force for galvanic corrosion between them. However, the tendency of galvanic corrosion is low, and the corrosion probably will not occur.

Linear polarization. Fig. 2 presents the linear polarization resistance curves of the two steel bars while interacting with

Table 3 Fitted electrochemical corrosion parameters from the Tafel curves

\begin{tabular}{llllc}
\hline & $E_{\text {corr }} / \mathrm{mV}$ & $i_{\text {corr }} / \mu \mathrm{A}$ & $b_{\mathrm{a}} / \mathrm{mV} \mathrm{dec}^{-1}$ & $b_{\mathrm{c}} / \mathrm{mV} \mathrm{dec}^{-1}$ \\
\hline LA-CR & -601.277 & 1.18 & 290.435 & 136.875 \\
LA-LC & -707.976 & 2.192 & 163.839 & 99.463 \\
MA-CR & -496.251 & 0.38 & 219.214 & 159.672 \\
MA-LC & -613.031 & 1.258 & 316.974 & 118.594 \\
HA-CR & -443.543 & 0.123 & 165.278 & 161.204 \\
HA-LC & -477.152 & 0.358 & 217.836 & 182.683
\end{tabular}

chloride ions in simulated concrete pore solutions with different $\mathrm{pH}$.

It can be seen from Fig. 2 that under the attack of chloride ions and at the same $\mathrm{pH}$, the linear polarization resistance of CR was greater than that of LC, indicating that the corrosion resistance of CR is better than that of LC. It can also be seen from Fig. 2 that with increasing $\mathrm{pH}$, the linear polarization resistance of $\mathrm{CR}$ and $\mathrm{LC}$ increased to different extents. Additionally, the difference between the linear polarization resistance of CR and LC also increased, suggesting that the corrosion resistance of the two steel bars was improved with increasing $\mathrm{pH}$ and that the improvement in the corrosion resistance of CR was even more pronounced. This is mainly because when the chloride ion concentration was $5 \mathrm{~mol} \mathrm{~L}^{-1}$, the passivation of CR and LC was enhanced with increasing $\mathrm{pH} .{ }^{9}$ Furthermore, even if the passivation film of CR is destroyed in highly alkaline environments and under chloride ion penetration, CR can still selfrepair. In contrast, LC has very poor self-repair capabilities. ${ }^{25}$

Tafel curves. Fig. 3 shows the Tafel curves of the two steel bars attacked by chloride ions in simulated concrete pore solutions with different $\mathrm{pH}$.

It can be seen from Fig. 3 that the anode zones of each polarization curve exhibited active dissolution characteristics and the cathode zones were controlled by ionization of oxygen and oxygen diffusion. At the same $\mathrm{pH}$, when the Tafel curve of LC was used as a reference, the Tafel curve of CR shifted up and to the left. When the $\mathrm{pH}=9.0$, the shapes of the cathode polarization curves of LC and CR are similar, indicating that the 
(a)
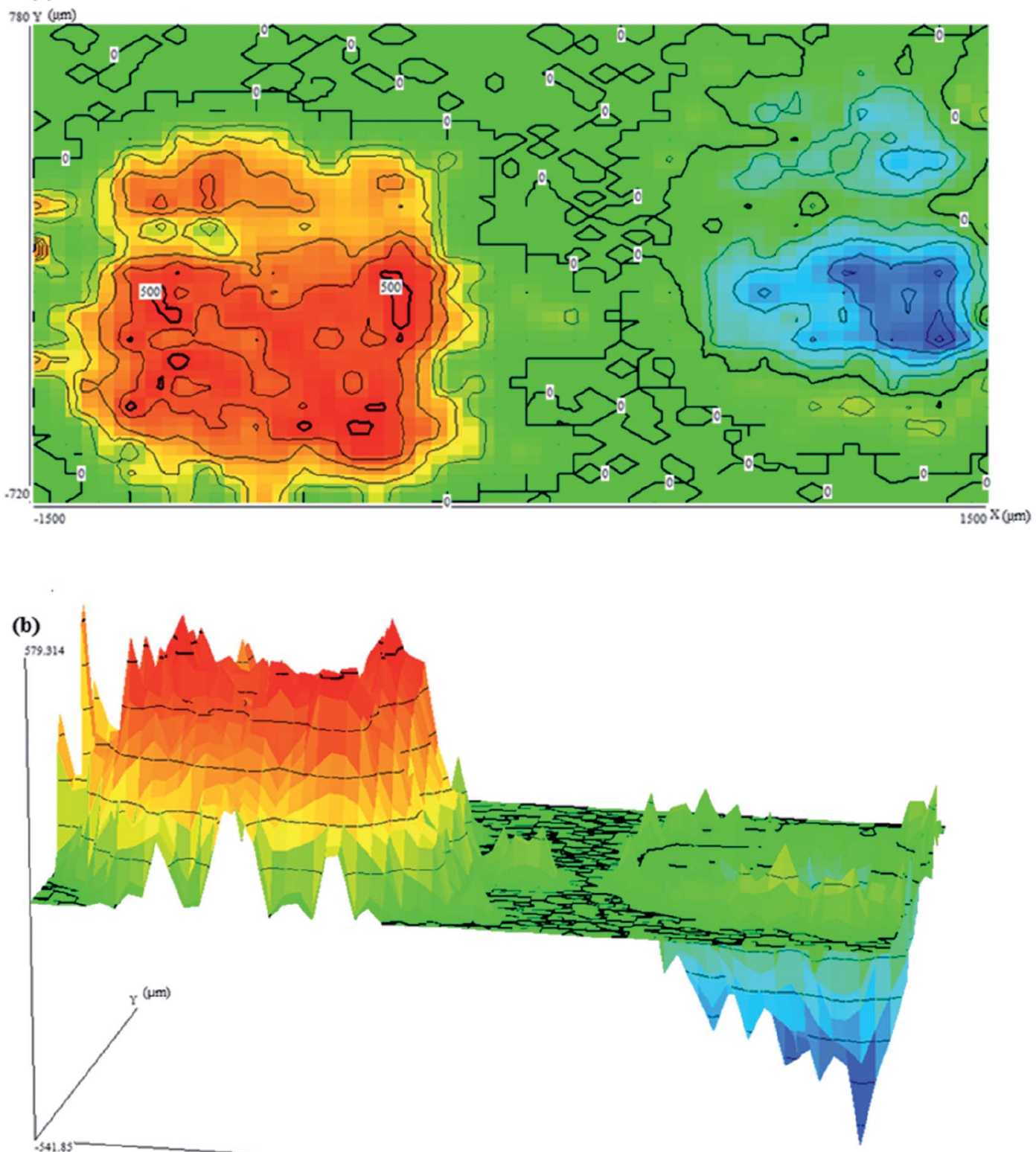

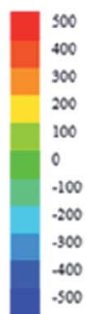

Current Density $\left(\mu \mathrm{A} \cdot \mathrm{cm}^{-2}\right)$

Fig. 4 SVET current density maps when CR and LC are connected at $\mathrm{pH}=9.0$ in (a) two-dimensions and (b) three-dimensions.

cathodic corrosion kinetic processes are the same. For the anodic polarization part, CR exhibited features characteristic of pitting corrosion. The balance potential of LC was lower than that of CR, indicating that LC had a greater corrosion tendency. When the $\mathrm{pH}=11.3$, for the cathodic polarization part of the curve, both LC and CR exhibited a certain degree of concentration polarization, whereas for the anode polarization part, LC exhibited features characteristic of corrosion acceleration and pitting corrosion. The polarization curve of LC markedly shifted to the right, leading to an increased corrosion rate. When the $\mathrm{pH}=13.6$, the polarization curves of CR and LC were similar and the cathode exhibited features characteristic of pitting corrosion.
Table 3 shows the electrochemical corrosion parameters obtained from fitting the Tafel curves.

It can be seen from Table 3 that at the same $\mathrm{pH}$, the $E_{\text {corr }}$ of LC was smaller than that of CR. Galvanic corrosion is related to the $E_{\text {corr }}$ of metals. The greater the difference between the $E_{\text {corr }}$ of the two metals, the more the high-potential cathode is protected and the more easily the low-potential anode is corroded. Therefore, there is a known tendency for galvanic corrosion to occur when LC and CR are in contact. Additionally, LC (as the anode) corrodes first while CR (as the cathode) is protected. The difference between the $E_{\text {corr }}$ of the two electrodes was approximately $100 \mathrm{mV}$ when the $\mathrm{pH}$ was 9.0 and approximately $30 \mathrm{mV}$ when the $\mathrm{pH}$ was 13.6. These results showed that with 
(a)
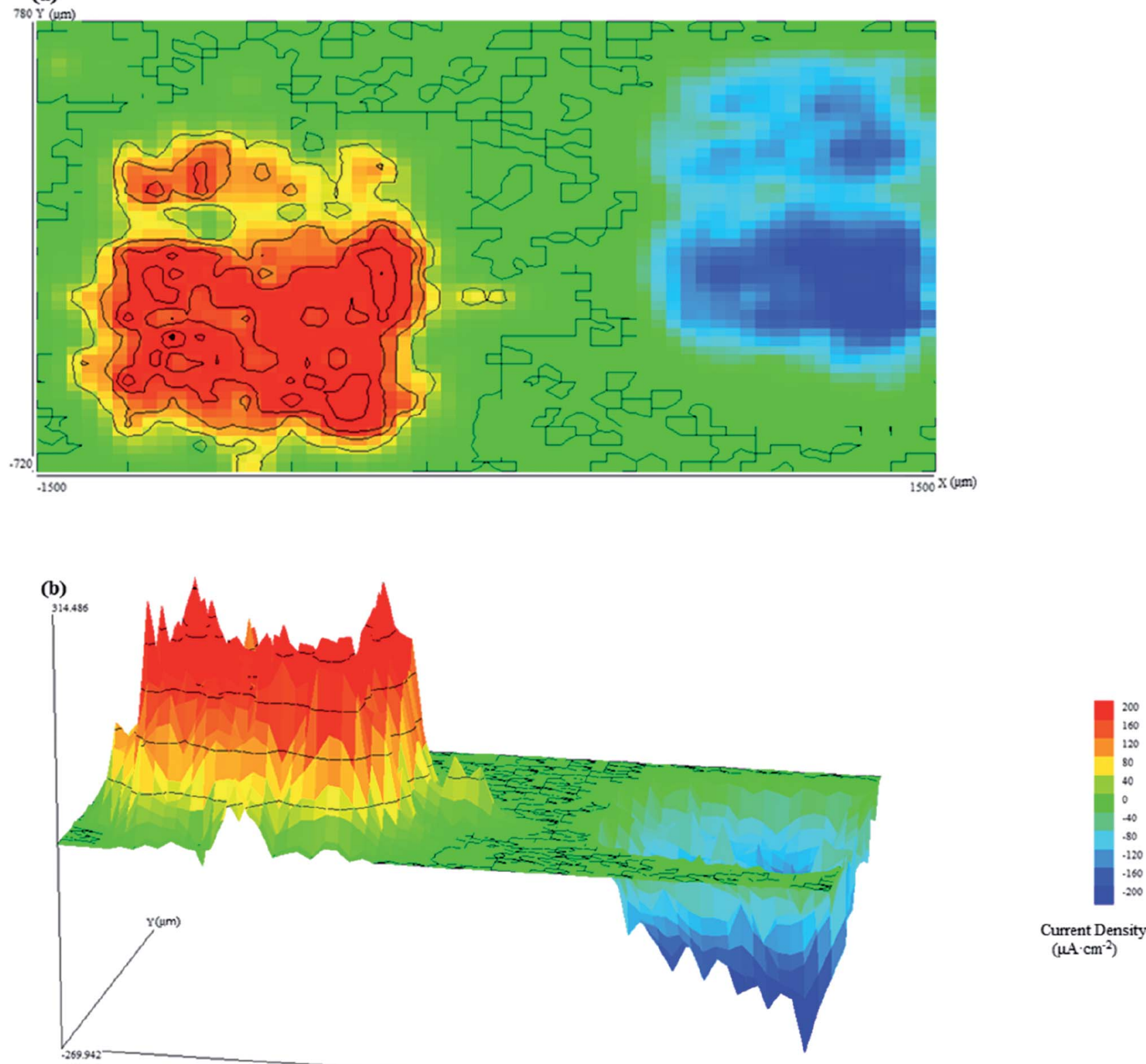

Current Density $\left(\mu \mathrm{A} \cdot \mathrm{cm}^{-2}\right)$

(a) Two-dimensional and (b) three-dimensional SVET current density maps of connected CR and LC samples at $\mathrm{pH}=11.3$.

increasing $\mathrm{pH}$, the difference between the $E_{\text {corr }}$ of LC and CR decreased and the driving force of the galvanic corrosion between the two electrodes decreased. Table 3 shows that, at the same $\mathrm{pH}$, the $i_{\text {corr }}$ of LC was greater than that of CR and that CR exhibited better corrosion resistance than LC. With increasing $\mathrm{pH}$, the $i_{\text {corr }}$ of both CR and LC decreased, indicating that CR and LC exhibited improved corrosion resistance with increasing $\mathrm{pH}$. For example, the $i_{\text {corr }}$ of CR and LC was smallest when the pH was 13.6, suggesting that CR and LC are resistant to corrosion under these conditions. Table 3 shows that $b_{\mathrm{a}}>b_{\mathrm{c}}$ for CR and LC, indicating that the anodic reaction is the controlling step in the overall reaction of CR and LC.
Fig. 3 and Table 3 show that when galvanic corrosion occurs, it is determined by both the cathodic polarization of CR and the anodic polarization of LC. Reduction occurred on the CR cathode, i.e. $\mathrm{O}_{2}+2 \mathrm{H}_{2} \mathrm{O}+4 \mathrm{e}^{-} \rightarrow 4 \mathrm{OH}^{-}$, whereas the oxidation of metals was developed on the LC anode, i.e. $\mathrm{Fe}-2 \mathrm{e}^{-} \rightarrow \mathrm{Fe}^{2+}$. Under alkaline conditions, $\mathrm{Fe}^{2+}$ reacted with $\mathrm{OH}^{-}$in the solution to generate $\mathrm{Fe}(\mathrm{OH})_{2}$. Because oxygen was not removed from the solution, the generated $\mathrm{Fe}(\mathrm{OH})_{2}$ was rapidly oxidized by $\mathrm{O}_{2}$ dissolved in the solution to generate $\mathrm{Fe}(\mathrm{OH})_{3}$, which was then rapidly decomposed to $\mathrm{Fe}_{2} \mathrm{O}_{3}$.

Fig. 3 and Table 3 show that at the same cathodic polarization potential, higher $\mathrm{pH}$ values produced lower current densities on $\mathrm{CR}$. This occurs because higher $\mathrm{pH}$ values 
(a)
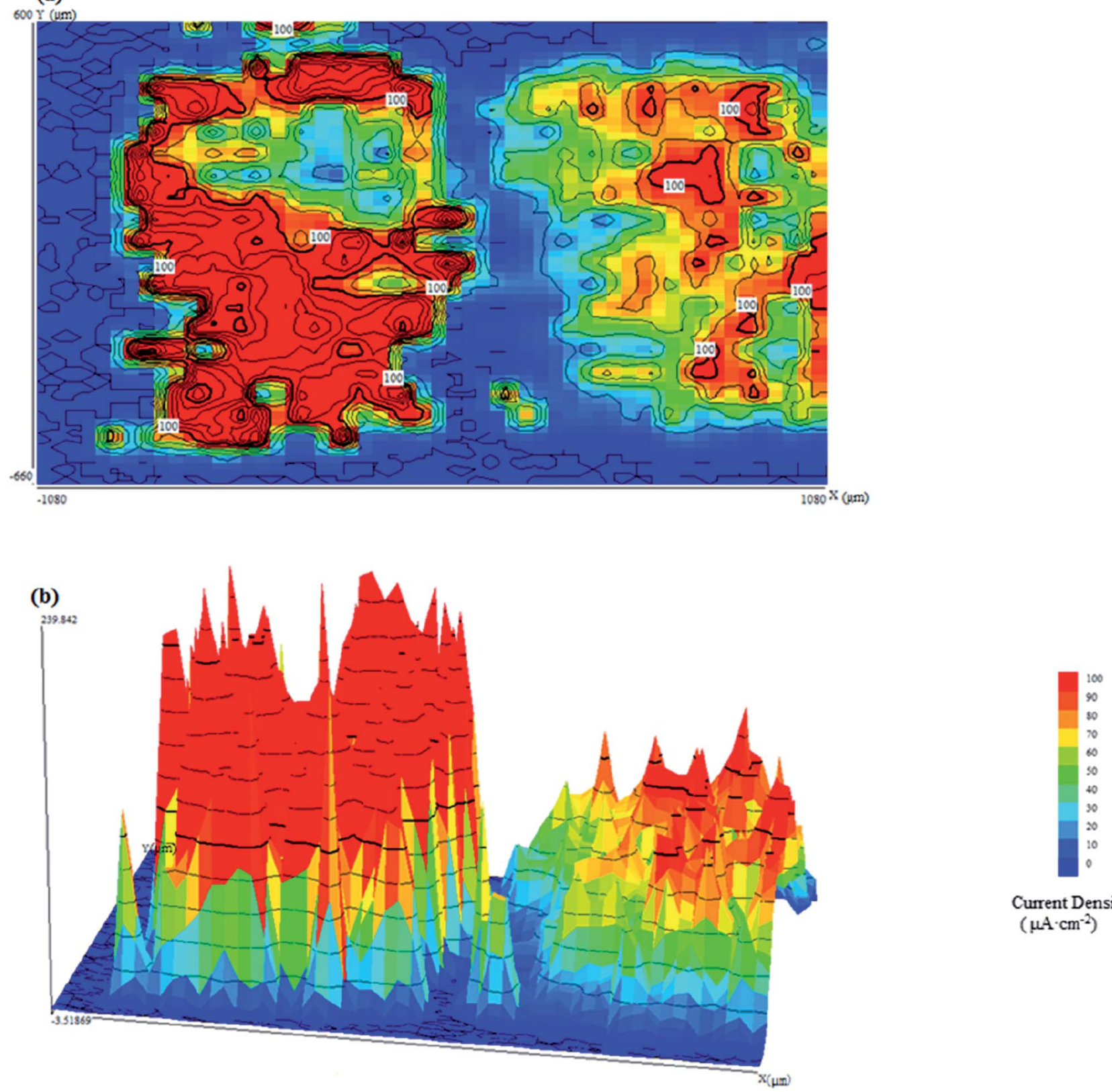

Current Density $\left(\mu \mathrm{A} \cdot \mathrm{cm}^{-2}\right)$

Fig. 6 (a) Two-dimensional and (b) three-dimensional SVET current density maps when CR and LC are connected at pH = 13.6.

enhanced the passivation of the steel bar surface and decreased the concentration of oxygen that penetrated the oxidized film to reach the sample surface and participate in the cathodic reaction. As a result, the current density decreased. For LC, at the same anodic polarization potential, higher $\mathrm{pH}$ values decreased the current density because the increased concentration of $\mathrm{OH}^{-}$ in the solution increased the accumulation of corrosion products on the surface of the electrodes, which affected the dissolution and diffusion rates of cations in the anodic process and thus decreased the reaction rate. As a result, the current density decreased. Because the rates of the reactions on the LC and CR surfaces are controlled by the anodic reaction, when galvanic corrosion occurs between CR and LC, the overall electrochemical reaction of the galvanic electrodes is controlled by the dissolution and diffusion rates of the cations, and the corrosion rate of the galvanic couple decreases with increasing $\mathrm{pH}$.

SVET. Fig. 4 shows the SVET current density maps when CR and $\mathrm{LC}$ are connected at $\mathrm{pH}=9.0$, (a) shows the twodimensional map and (b) shows the three-dimensional map. It should be highlighted that the SVET current density of LC was in the left side (the red region), and the SVET current density of CR was in the right side (the blue region) in all the SVET current density maps.

It can be seen from Fig. 4 that there are two corresponding peaks in the current density map. As predicted, galvanic corrosion occurred on LC and CR, with LC serving as the anode and CR serving as the (protected) cathode. Due to the oxidation reaction and the release of metal cations from the surface of $\mathrm{LC}$, 

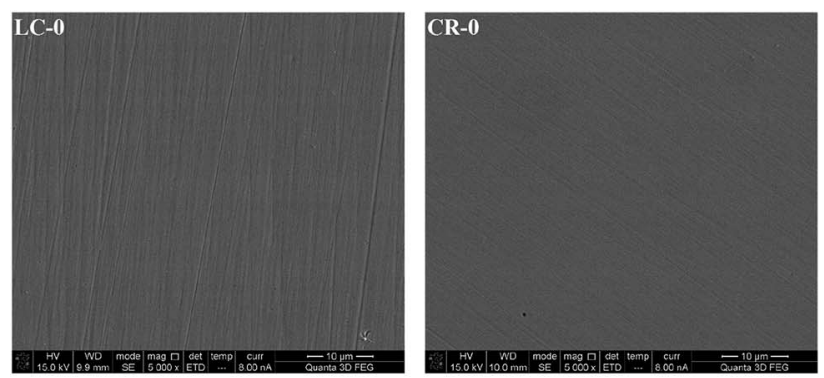

(a)
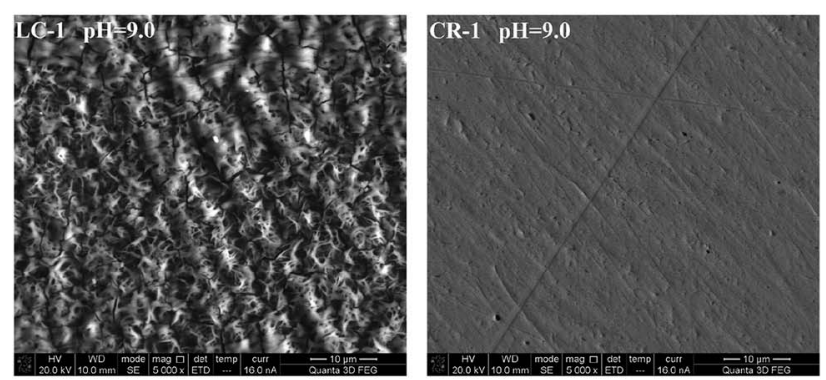

(b)
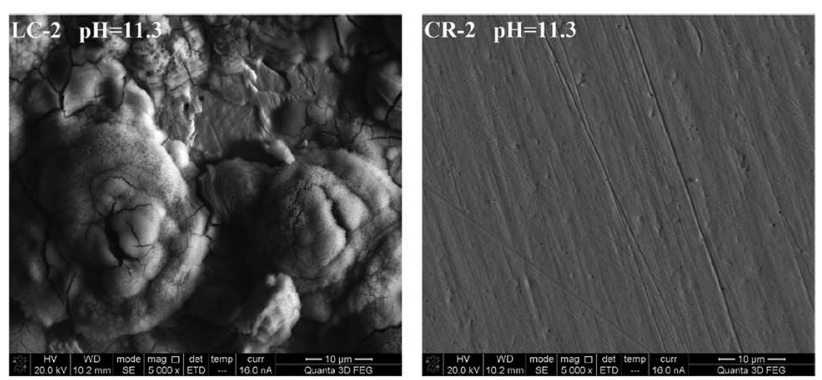

(c)
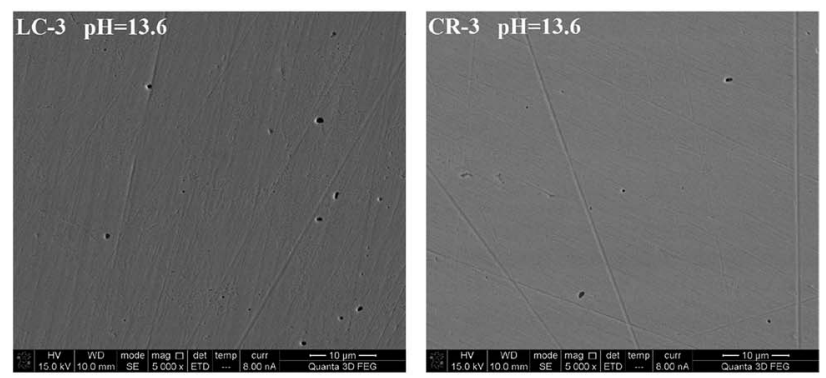

(d)

Fig. 7 Surface morphology of corroded CR and LC: (a) LC-O and CR0 are the original surfaces of the LC and CR samples; (b) LC-1 and CR-1 refer to the surfaces of the $L C$ and $C R$ after galvanic corrosion in solution LA; (c) LC-2 and CR-2 refer to the surfaces of LC and CR after galvanic corrosion in solution MA; (d) LC-3 and CR-3 refer to the surfaces of LC and CR after galvanic corrosion in solution $\mathrm{HA}$.

its current density was positive. ${ }^{26}$ In contrast, due to the reduction reaction and the formation of hydroxide ions on the surface of CR, its current density was negative. As seen from Fig. 4(a), the current densities at CR and LC were approximately $500 \mu \mathrm{A} \mathrm{cm}^{-2}$. However, the current distribution of the anode and cathode regions did not possess the same characteristics: the current on the surface of LC was uniformly distributed, while that of CR exhibited local differences. Additionally, Fig. 4(b) shows that the uniform current density distribution on
LC and the sharp current density peaks on CR are probably attributable to the attack of dissolved chloride ions on their surfaces.

Fig. 5 shows the SVET current density maps of CR and LC when they are in contact at $\mathrm{pH}=11.3$, including (a) twodimensional and (b) three-dimensional maps.

It can be seen from Fig. 5 that when galvanic corrosion occurred on LC and CR, LC served as the anode and CR as the cathode. The current density of CR and LC were both approximately $200 \mu \mathrm{A} \mathrm{cm}^{-2}$. However, the current distributions at the anodic and cathodic regions were different. The current density of the anodic region was greater than that of the cathodic region.

The above analysis shows that when the $\mathrm{pH}$ is 9.0 or 11.3 , galvanic corrosion occurs when CR and LC are coupled. Additionally, at high $\mathrm{pH}$, a small current is used to maintain electrochemical corrosion process when the anode and cathode are in alkaline media. Because LC exhibited a high, broadly distributed current density due to its high surface activity, it was considered to have uniform corrosion, although some pitting corrosion may have occurred. In contrast, CR was protected from the galvanic corrosion, and only high and sharp cathodic current peaks were observed, which indicated the existence of pitting corrosion from chloride ions. Additionally, the current density was smaller when the $\mathrm{pH}$ was 11.3 compared to that when the $\mathrm{pH}$ was 9.0 due to several factors. First, the high $\mathrm{pH}$ decreased the potential difference between $\mathrm{CR}$ and LC, decreasing the driving force of the galvanic corrosion. Second, when the chloride ion concentration was $5 \mathrm{~mol} \mathrm{~L}^{-1}$, the passivation capabilities of CR and LC in the simulated concrete pore solution were improved, thus resulting in improvements in the corrosion resistances of CR and LC. ${ }^{22}$

Fig. 6 shows the SVET current density maps when CR and LC are connected at $\mathrm{pH}=13.6$, including (a) a two-dimensional map and (b) a three-dimensional map.

When the $\mathrm{pH}$ was 13.6, even though LC and CR were in contact, galvanic corrosion did not occur, leaving only regular corrosion to occur on each electrode because the difference between the potentials of CR and LC was small. As a result, the driving force was not sufficient to produce galvanic corrosion. The current density for the corrosion of LC was large, approximately $100 \mu \mathrm{A} \mathrm{cm}^{-2}$, while the current density for the corrosion of CR was small, approximately $50 \mu \mathrm{A} \mathrm{cm} \mathrm{cm}^{-2}$. This is because under highly alkaline conditions, it is easier for CR to form a passivation film than for LC to do so. Furthermore, even under the corrosion of chloride ions, CR still possesses an excellent capability to repair its passivation film. Fig. 6(b) shows that there were many current density peaks on the CR and LC. Past research $^{23}$ has shown that under corrosive conditions for CR and LC, pitting corrosion predominates, which explains the many sharp current density peaks in the SVET maps.

SEM and DHM. Fig. 7 shows the surface morphology of corroded CR and LC.

It can be seen from Fig. 7(a) that the untested LC and CR exhibited smooth surfaces. Fig. 7(b) shows that after the galvanic corrosion of LC and CR in the simulated concrete pore solution with a $\mathrm{pH}$ of 9.0 and a chloride ion concentration of 

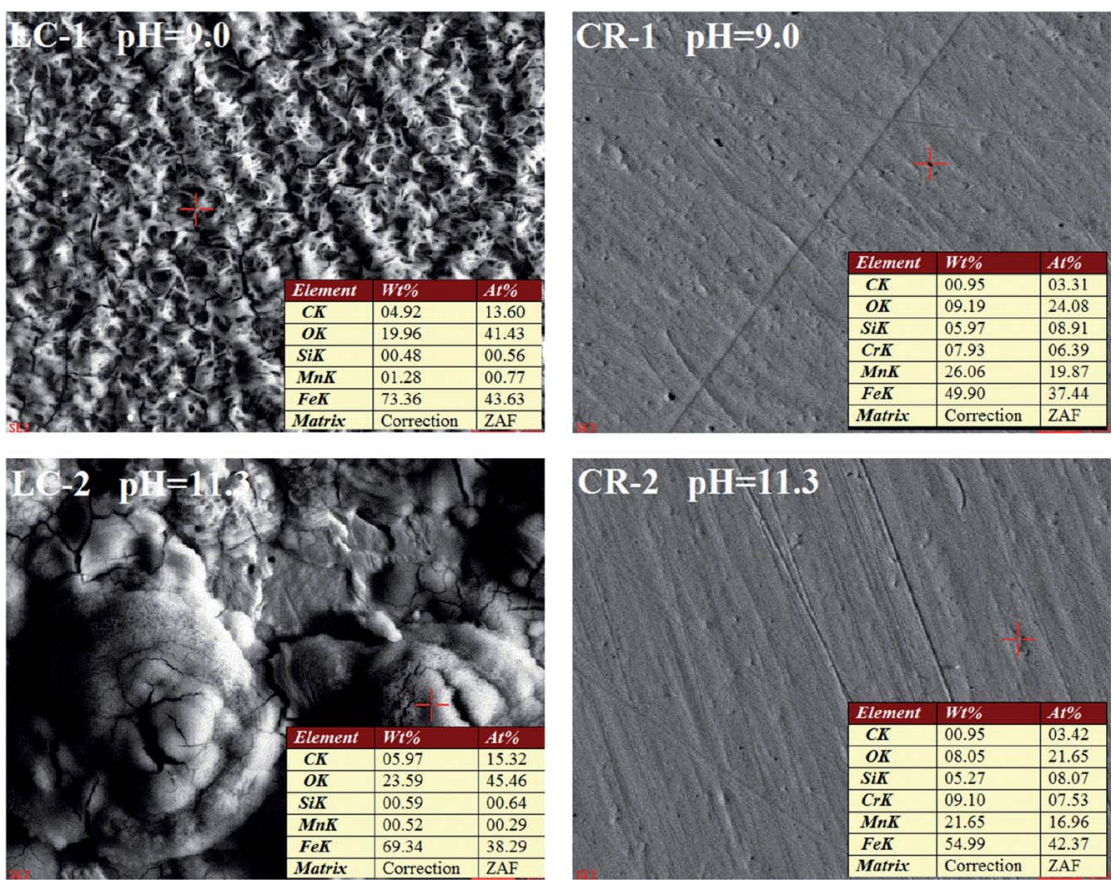

Fig. 8 EDS of CR and LC after galvanic corrosion in solutions with pH of 9.0 and 11.3.

$5 \mathrm{~mol} \mathrm{~L}^{-1}$, the surface of LC was severely corroded, generating a large amount of corrosion products that were evenly distributed on the surface. In contrast, the surface of CR was roughened and only small pits appeared. Fig. 7(c) shows that after the galvanic corrosion of LC and CR in the simulated concrete pore solution with a pH of 11.3 and a chloride ion concentration of $5 \mathrm{~mol} \mathrm{~L}^{-1}$, the surface of LC had accumulated corrosion products and obvious corrosions pits. In contrast, the surface of CR was smooth and pits appeared only at certain locations. Fig. 7(d) shows that in the simulated concrete pore solution with a $\mathrm{pH}$ of 13.6 and a chloride ion concentration of $5 \mathrm{~mol} \mathrm{~L}^{-1}$, CR and LC both exhibited substantial corrosion and obvious corrosion pits on their surfaces, although the corrosion was more severe on LC than on CR. The above analysis shows that when galvanic corrosion occurs on CR and LC, the corrosion is more severe for the anode (LC) than for the protected cathode (CR). To further analyse the corrosion products from the galvanic corrosion of LC and CR, EDS was performed on LC and CR samples corroded in solutions with $\mathrm{pH}$ of 9.0 and 11.3.
Fig. 8 shows the EDS of CR and LC after galvanic corrosion in solutions with $\mathrm{pH}$ of 9.0 and 11.3.

It can be seen from Fig. 8 that the main corrosion products on the LC surface after galvanic corrosion were iron oxides. There was some corrosion on the surface of CR that occurred at positions with higher Mn content. It is hypothesized that the pitting corrosion of CR is related to the doping of Mn. Under the attack of chloride ions, corrosion first developed in the $\mathrm{Mn}$ inclusions in CR and further developed into corrosion pits. To better understand the surface morphology of CR, DHM was performed.

Fig. 9 shows the three-dimensional surface morphology of CR and LC after galvanic corrosion in solutions with $\mathrm{pH}$ of 9.0 and 11.

It can be seen from Fig. 9 that when the $\mathrm{pH}=9.0$, the surface of CR was roughened after galvanic corrosion, and there were pits with a nanoscale depth. When the $\mathrm{pH}=11.3$, the surface of CR was rather smooth but had pits with a nanoscale depth at certain locations.
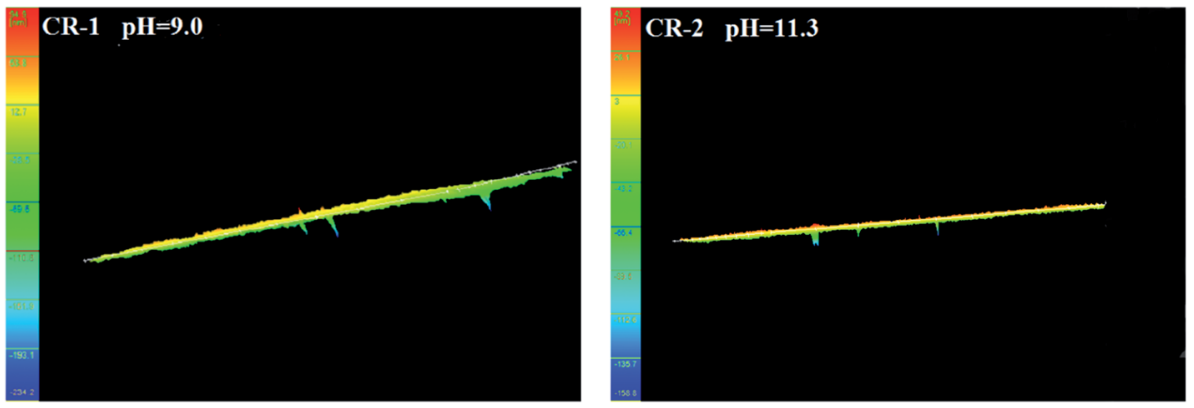

Fig. 9 Three-dimensional surface morphology of CR and LC after galvanic corrosion in solutions with pH of 9.0 and 11 . 


\section{Conclusions}

In this study, OCP, SVET, SEM and reflection DHM were used to study the galvanic corrosion of novel CR and LC in simulated concrete pore solutions with different $\mathrm{pH}$ and $5 \mathrm{~mol} \mathrm{~L}^{-1}$ chloride ions. The following conclusions were obtained:

(1) While being attacked by chloride ions, CR and LC showed corrosion behaviour that is significantly affected by the $\mathrm{pH}$ of the simulated concrete pore solution that they contact. With increasing $\mathrm{pH}$, the potential between $\mathrm{CR}$ and LC decreased and the driving force for the galvanic corrosion decreased. During galvanic corrosion, LC served as the anode and CR served as the cathode.

(2) When the pH was 9.0, galvanic corrosion occurred on both CR and LC. Additionally, the corrosion rate was high. Pitting corrosion was locally developed on CR whereas uniform corrosion predominated on LC. In both cases, there was apparent accumulation of corrosion products on the surface of samples. When the $\mathrm{pH}$ was 11.3 , galvanic corrosion occurred when CR and LC were in contact. CR had a relatively smooth surface, with only a small amount of pitting corrosion. In contrast, both pitting corrosion and uniform corrosion appeared on LC. There was apparent pitting corrosion and an accumulation of corrosion products. When the $\mathrm{pH}$ was 13.6, there was no galvanic corrosion when CR and LC were in contact, and pitting corrosion predominated on CR and LC.

(3) With chloride ion corrosion and low $\mathrm{pH}$, the galvanic corrosion between CR and LC cannot be ignored. Therefore, galvanic corrosion occurred easily between CR and LC at regions with severe chloride ion corrosion and carbonization. Therefore, it is not recommended to put CR and LC in contact in those regions.

\section{Conflicts of interest}

There are no conflicts of interest to declare.

\section{Acknowledgements}

The authors greatly acknowledge the support from 2016YFC0305100, the National Natural Science Foundation of China (No. 51438003, 51278098, 51578143, 51678144), the National Basic Research Program of China "973 Project" (No. 2015CB655105), Technological Development Projects of China Railway Engineering Corporation (2014G004-F), and the Industry-University Research Cooperative Innovation Fund of Jiangsu Province (No. BY2013091).

\section{References}

1 B. Sanz, J. Planas and J. M. Sancho, Cem. Concr. Res., 2017, 101, 68.

2 M. M. Mirsayar, K. Huang and G. Z. Dan, Transp. Res. Rec., 2016, 2590, 10.

3 H. P. Seifert and S. Ritter, Corros. Sci., 2016, 108, 134.

4 R. Liu, L. Jiang, J. Xu, C. Xiong and Z. Song, Constr. Build. Mater., 2014, 56, 16.

5 H. Binici, H. Zengin, G. Zengin and F. Yasarer, Corros. Sci., 2008, 50, 2140.

6 J. H. Jiang and Y. S. Yuan, Constr. Build. Mater., 2013, 44, 287. 7 F. Shaheen and B. Pradhan, Cem. Concr. Res., 2017, 91, 73.

8 M. Serdar, C. Meral, M. Kunz, D. Bjegovic, H. R. Wenk and P. J. Monteiro, Cem. Concr. Res., 2015, 71, 93.

9 Z. Ai, W. Sun, J. Jiang, D. Song and H. Ma, Materials, 2016, 9, 749.

10 J. Jiang, D. Wang, H.-y. Chu, H. Ma, Y. Liu, Y. Gao, J. Shi and W. Sun, Materials, 2017, 10, 412.

11 J. Shi, W. Sun, J. Jiang and Y. Zhang, Constr. Build. Mater., 2016, 111, 805.

12 C. F. Dong, K. Xiao, X. G. Li and Y. F. Cheng, Wear, 2010, 270, 39.

13 H. N. Krogstad and R. Johnsen, Corros. Sci., 2017, 121, 43.

14 C. M. Abreu, M. J. Cristóbal, M. F. Montemor, X. R. Nóvoa, G. Pena and M. C. Pérez, Electrochim. Acta, 2002, 47, 2271.

15 J. Z. Ai, X. P. Guo and Z. Y. Chen, Appl. Surf. Sci., 2006, 253, 683.

16 Z. Liu, M. Curioni, P. Jamshidi, A. Walker, P. Prengnell, G. E. Thompson and P. Skeldon, Appl. Surf. Sci., 2014, 314, 233.

17 H. Zhang, X. Pang and K. Gao, Appl. Surf. Sci., 2018, 442, 446. 18 M. Saremi and E. Mahallati, Cem. Concr. Res., 2002, 32, 1915.

19 J. K. Boah, S. K. Somuah and P. Leblanc, Corrosion, 1990, 46, 153.

20 C. Alonso, C. Andrade, M. Castellote and P. Castro, Cem. Concr. Res., 2000, 30, 1047.

21 C. Alonso, M. Castellote and C. Andrade, Electrochim. Acta, 2002, 47, 3469.

22 C. Baek and J. D. Lee, Constr. Build. Mater., 2009, 23, 1902.

23 A. Davoodi, M. Pakshir, M. Babaiee and G. R. Ebrahimi, Corros. Sci., 2011, 53, 399.

24 C. Cao, Principles of Electrochemistry of Corrosion, Chemical Industry Press, Beijing, 2004.

25 J. Jiang, Y. Liu, H.-y. Chu, D. Wang, H. Ma and W. Sun, Materials, 2017, 10, 903.

26 Q. Ni, X. Xia, J. Zhang, N. Dai and Y. Fan, Electrochim. Acta, 2017, 247, 207. 